Conclusions: Patients with RA and HF have an unfavourable prognosis. One third of them were hospitalised for HF or died during follow-up. In addition to patient characteristics, smoking, insufficiently controlled inflammation and treatment with glucocorticoids significantly increased the risk of hospitalisation or death.

Acknowledgements: RABBIT is supported by a joint, unconditional grant from AbbVie, Bristol-Myers Squibb, Celltrion, Hexal, Lilly, MSD Sharp and Dohme, Pfizer, Roche, Samsung Bioepis, Sanofi-Aventis und UCB.

Disclosure of Interest: Y. Meissner Speakers bureau: Pfizer, M. Schäfer: None declared, B. Manger: None declared, M. Zänker Speakers bureau: Celgene, MSD, Roche, W. Ochs: None declared, J. Listing: None declared, A. Strangfeld Speakers bureau: AbbVie, BMS, Lilly, MSD, Pfizer, Roche, UCB DOI: 10.1136/annrheumdis-2018-eular.3979

A. Blanken ${ }^{1}$, R. Agca ${ }^{1}$, A. Voskuijl1, R. Boellaard², C. van der Laken¹, M. Nurmohamed ${ }^{1} .{ }^{1}$ Amsterdam Rheumatology and immunology Center, Reade, VUmc and AMC; ${ }^{2}$ Radiology and Nuclear Medicine, VU University Medical Centre, Amsterdam, Netherlands

Background: Patients with rheumatoid arthritis (RA) have an elevated cardiovascular (CV) disease risk, mostly explained by both an increased prevalence of traditional $\mathrm{CV}$ risk factors and the presence of systemic inflammation that accelerates atherosclerosis. There is accumulating evidence that anti-inflammatory treatment for RA reduces this $\mathrm{CV}$ risk. A non-invasive tool for detecting vascular wall inflammation in atherosclerosis is 18F-Fluorodeoxyglucose-Positron Emission Tomography/Computed Tomography (18F-FDG-PET/CT)

Objectives: To study the effect of anti-inflammatory treatment with methotrexate (MTX) or adalimumab on vascular wall inflammation in RA assessed by $18 \mathrm{~F}$ FDG-PET/CT.

Methods: 18F-FDG-PET/CT was done in patients with active early RA starting MTX $(n=25)$ and active established RA starting adalimumab $(n=24)$ before and after 6 months of therapy, and in osteoarthritis controls (OA; $n=29)$. 18F-FDG uptake in arterial wall was determined by standardised uptake values (SUV). Volumes of interest covering the arterial segment with the highest 18F-FDG were defined to derive the maximum SUV (SUVmax) in the ascending, descending and abdominal aorta and the aortic arch. Global arterial uptake was estimated using the mean SUVmax of the four arterial segments.

Results: Mean age was $65 \pm 9$ for early RA, $61 \pm 7$ for established RA and $63 \pm 5$ years for OA controls. Median disease duration was 2.1 (interquartile range (IQR) 1.3-3.3) weeks for early RA and 6.9 (IQR 1.8-13.9) years for established RA. DAS28 was $4.9 \pm 1.0$ and $4.4 \pm 1.0$ at baseline and declined to $3.1 \pm 1.3$ and $2.8 \pm 1.4$ after 6 months therapy, respectively.

At baseline mean SUVmax was $1.86 \pm 0.38$ for early RA, $1.68 \pm 0.43$ for established RA and $1.56 \pm 0.41$ for OA controles. SUVmax tended to decline more in early RA patients when compared to established RA $(1.86 \pm 0.38$ to $1.79 \pm 0.43(-3.7 \%)$ and $1.68 \pm 0.43$ to $1.63 \pm 0.43(-3.0 \%)$, respectively). SUVmax in most arterial segments declined after 6 months of therapy (table 1). The most prominent decline in SUV-

Conclusions: A decline in global arterial SUVmax and in most of arterial segments was found in both early and established RA patients after 6 months of MTX and/or adalimumab, suggesting that anti-inflammatory therapy with either MTX and/or adalimumab decreases arterial wall inflammation and thus CV risk in RA.

Disclosure of Interest: None declared

DOI: 10.1136/annrheumdis-2018-eular.5660

\section{THU0143 VASCULAR WALL INFLAMATION IN RHEUMATOID ARTHRITIS PATIENTS DECREASES AFTER 6 MONTHS OF ANTI-INFLAMMATORY THERAPY WITH METHOTREXATE OR ADALIMUMAB AS MEASURED BY 18F-FDG-PET/CT} max was in de abdominal aorta in established RA patients $(-9.8 \%)$.

\section{THU0144}

PERFORMANCE OF THE ERS-RA CARDIOVASCULAR RISK PREDICTION TOOL: EXTERNAL VALIDATION IN A LARGE SWEDISH COHORT WITH RA

L. Ljung ${ }^{1,2}$, P. Ueda ${ }^{2}$, K.P. Liao ${ }^{3}$, J.D. Greenberg ${ }^{4,5}$, C.J. Etzel ${ }^{5}$, D.H. Solomon ${ }^{3}$, J. Askling ${ }^{2} .{ }^{1}$ Umeå University, Umeå; ${ }^{2}$ Karolinska Institutet, Stockholm, Sweden; ${ }^{3}$ Brigham and Women's Hospital, Boston, MA; ${ }^{4}$ New York University School of Medicine, New York; ${ }^{5}$ Corrona LLC, Waltham, MA, USA

Background: Risk prediction tools developed for the general population tend to underestimate the risk of cardiovascular $(C V)$ disease in patients with $\mathrm{RA}^{1}$. An accurate and RA-specific CV risk prediction tool would ideally be integrated as a routine part of clinical practice in rheumatology, to identify patients with increased $\mathrm{CV}$ risks. For example, 10 year CV risks above $7.5 \%$, or $10 \%$, could warrant specific preventive measures ${ }^{2,3}$. The ERS-RA was derived and internally validated in the US Corrona RA registry ${ }^{4}$. ERS-RA estimates the 10 year $\mathrm{CV}$ risk using dichotomous clinical variables, and includes variables on RA disease severity and activity.

Objectives: To assess the external validity of the ERS-RA in Swedish cohorts of patients with RA, with focus on the risk intervals of main clinical interest.

Methods: We identified two cohorts of patients with RA: (i) an "incident 2006 cohort" with RA patients in the Swedish Rheumatology Register from Jan 1, 2006 - Dec 31, 2011 who were also in the EIRA case-control study ( $n=2047$, mean age $55 \pm 13$ years, $72 \%$ women), and (ii) a "prevalent 2012 cohort" that included all RA patients in the Swedish Rheumatology Register between Jan 1, 2012 - Dec 31 2015 ( $n=14485$, mean age $61 \pm 14$ years, $74 \%$ women). The 10 year $C V$ risk was estimated using ERS-RA. Patients with a history of myocardial infarction or stroke were excluded. All patients were followed for the first of any of the following: a CV event (myocardial infarction, stroke, cardiovascular death), death, 10 years of follow-up, or Dec 31, 2015. Ten-year CV rates were expressed using the KaplanMeier method. In the prevalent 2012 cohort, the 10 year event rates were extrapolated from the observed (maximally four-year) rates. ${ }^{5}$ The C-statistic was estimated to assess discrimination. A measure of model calibration, the observed event rates were compared with the mean predicted 10 year risks.

Results: The C-statistic was 0.75 for both cohorts. Most patients had an estimated $\mathrm{CV}$ risk $<5 \%$ or of $>10 \%$ (See table 1). An accurate risk prediction was observed for estimated risks in the intervals $<5 \%$, and 5.0 to $<7.5 \%$. ERS-RA underestimated risk in the interval 7.5 to $<10 \%$ (see table 1 and figure 1 ).

Abstract THU0144 - table 1. and figure 1. Comparisons of the mean estimated and the observed 10-year CV risks within groups of estimated risk levels.

\begin{tabular}{|c|c|c|c|c|c|}
\hline & $\begin{array}{c}\text { Groups of } \\
\text { estimated } \\
10 \text { year } \\
\text { risk }\end{array}$ & $\begin{array}{c}\mathrm{N} \\
\text { patients } \\
(\%)\end{array}$ & $\begin{array}{c}\text { Mean } \\
\text { estimated } \\
10 \text { year } \\
\text { risk (\%) }\end{array}$ & $\begin{array}{c}\text { Observed } \\
10 \text { year } \\
\text { rate }(\%)\end{array}$ & $\begin{array}{l}\text { Difference Observed rate } \\
\text { - Mean estimated risk }\end{array}$ \\
\hline Incident & $<5 \%$ & $884(48)$ & 2.5 & 2.3 & -0.2 \\
\hline \multirow{4}{*}{$\begin{array}{l}2006 \\
\text { Cohort }\end{array}$} & 5.0 & $282(15)$ & 6.2 & 5.7 & -0.5 \\
\hline & to $<7.5 \%$ & & & & \\
\hline & $\begin{array}{l}7.5 \\
\text { to }<10 \%\end{array}$ & $43(2)$ & 8.6 & 13.4 & 4.8 \\
\hline & $\geq 10.0 \%$ & $638(35)$ & 18.3 & 18.3 & 0 \\
\hline $\begin{array}{l}\text { Prevalent } \\
2012\end{array}$ & $<5 \%$ & $\begin{array}{l}4691 \\
(32)\end{array}$ & 2.7 & 1.9 & -0.8 \\
\hline \multirow[t]{3}{*}{ Cohort } & $\begin{array}{l}5.0 \\
\text { to }<7.5 \%\end{array}$ & $\begin{array}{c}1604 \\
(11)\end{array}$ & 6.2 & 4.0 & -2.2 \\
\hline & $\begin{array}{l}7.5 \\
\text { to }<10 \%\end{array}$ & $\begin{array}{l}1485 \\
(10)\end{array}$ & 8.6 & 12.0 & 3.4 \\
\hline & $\geq 10.0 \%$ & $\begin{array}{c}6705 \\
(46)\end{array}$ & 22.2 & 24.5 & 2.3 \\
\hline
\end{tabular}

Abstract THU0143 - Table 1. Arterial 18F-FDG uptake in RA patients before and after 6 months of therapy

\begin{tabular}{|c|c|c|c|c|c|c|c|}
\hline & \multirow{2}{*}{$\begin{array}{c}\text { OA } \\
\text { Baseline }\end{array}$} & \multicolumn{3}{|c|}{ Early RA } & \multicolumn{3}{|c|}{ Established RA } \\
\hline & & Baseline & $\begin{array}{c}6 \text { months } \\
\text { MTX }\end{array}$ & & Baseline & $\begin{array}{c}6 \text { months } \\
\text { adalimumab }\end{array}$ & \\
\hline SUVmax ascending aorta & $1.55 \pm 0.44$ & $1.82 \pm 0.38$ & $1.77 \pm 0.38$ & $-2.7 \%$ & $1.69 \pm 0.61$ & $1.60 \pm 0.44$ & $-5.3 \%$ \\
\hline SUVmax descending aorta & $1.57 \pm 0.42$ & $1.93 \pm 0.53$ & $1.81 \pm 0.47$ & $-6.2 \%$ & $1.65 \pm 0.39$ & $1.71 \pm 0.47$ & $+3.6 \%$ \\
\hline SUVmax abdominal aorta & $1.62 \pm 0.43$ & $1.84 \pm 0.44$ & $1.81 \pm 0.58$ & $-1.6 \%$ & $1.73 \pm 0.61$ & $1.56 \pm 0.45$ & $-9.8 \%$ \\
\hline SUVmax aortic arch & $1.51 \pm 0.48$ & $1.85 \pm 0.48$ & $1.76 \pm 0.45$ & $-4.9 \%$ & $1.66 \pm 0.40$ & $1.64 \pm 0.59$ & $-1.2 \%$ \\
\hline $\begin{array}{l}\text { Mean SUVmax over } 4 \\
\text { segments }\end{array}$ & $1.56 \pm 0.42$ & $1.86 \pm 0.38$ & $1.79 \pm 0.43$ & $-3.7 \%$ & $1.68 \pm 0.43$ & $1.63 \pm 0.43$ & $-3.0 \%$ \\
\hline
\end{tabular}




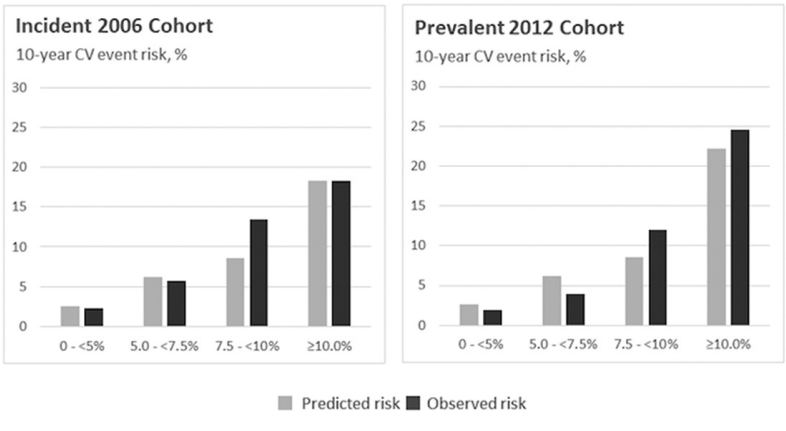

Conclusions: In a Swedish population with RA, ERS-RA performed well in identifying patients with a very low and very high CV 10 year CV risk. In clinical routine practice, ERS-RA could be used to identify low and high risk individuals, who might be considered for additional $\mathrm{CV}$ risk factor evaluation and subsequent intervention.

\section{REFERENCES:}

[1] Crowson CS, et al. Ann Rheum Dis. 2018.

[2] Stone NJ, et al. Circulation. 2014.

[3] https://www.nice.org.uk

[4] Solomon DH, et al. Arthritis Rheum. 2015.

[5] Cook NR, Ridker PM. JAMA Intern Med. 2014.

Disclosure of Interest: None declared

DOI: 10.1136/annrheumdis-2018-eular.2712

\section{THU0145 CHANGES IN BONE METABOLISM AND TRABECULAR BONE SCORE IN PATIENTS WITH EARLY RHEUMATOID ARTHRITIS}

A. Corrado, A. Mele, E. Sanpaolo, A. Trotta, R. Colia, F.P. Cantatore. Department of Medical and Surgical Sciences, Rheumatology Clinic -University of Foggia, Foggia, Italy

Background: Rheumatoid arthritis (RA) is a systemic inflammatory disease which can lead to bone and joint damage including local bone erosion and general osteoporosis. Dual X-ray Absorptiometry (DXA) is the established standard for measuring Bone Mineral Density (BMD), but it does not provide any informations about the bone microarchitecture, which is an essential parameter to define bone strength. The Trabecular Bone Score (TBS) is a new structural parameter that can be obtained by DXA scanning and it is related to bone microarchitecture and provides data on bone quality irrespective of bone density.

Objectives: The aim of this study is to evaluate the changes of BMD, TBS and bone remodelling parameters in subjects with recent-onset rheumatoid arthritis, treated or not with high doses of glucocorticoid, compared to age and sex matched healthy controls

Methods: The study included 42 subjects $(31 \mathrm{~F}, 11 \mathrm{M})$, fulfilling the $2010 \mathrm{EULAR} /$ ACR diagnostic criteria for RA and recent onset of joint symptoms ( $<6$ months of synovitis) (Early RA), which were treated according to the current EULAR guidelines. As control group, 25 sex and age matched healthy subjects (21F, $4 \mathrm{M})$ were recruited. Post-menopausal women were excluded from the study. Lumbar spine and femoral BMD and TBS were evaluated at recruitment and after 12 months. The following parameters of bone remodelling and regulatory cytokines were measured at recruitment and every 3 months for 12 months: type I N-terminal propeptide (P1NP), osteocalcin, alkaline phosphatase, sclerostin, dickkopf-1 (DKK1), osteoprotegerin (OPG), Receptor Activator of Nuclear Factor Kappa-B ligand (RANKL). The clinical and demographic characteristics, including disease activity index and quality of life, were also evaluated

Results: No difference in BMD (spine and hip) and TBS values were detected between Early RA and control group at recruitment time $\left(0,893 \mathrm{~g} / \mathrm{cm}^{2} \mathrm{vs} 0,972 \mathrm{~g} /\right.$ $\mathrm{cm}^{2} ; 0,790 \mathrm{~g} / \mathrm{cm}^{2}$ vs $0,770 \mathrm{~g} / \mathrm{cm}^{2} ; 1598$ vs 1521 respectively). After 12 months, the BMD at spine and hip and TBS values were significantly lower in patients with Early RA compared to healthy controls $\left(0,601 \mathrm{~g} / \mathrm{cm}^{2}\right.$ vs $1,011 \mathrm{~g} / \mathrm{cm}^{2} ; 0,560 \mathrm{~g} / \mathrm{cm} 2$ vs $0,981 \mathrm{~g} / \mathrm{cm}^{2} ; 1335$ vs 1488 respectively). After 12 months, patients treated with high-dose of corticosteroids showed lower mean TBS values compared to patients untreated or treated with low-dose of corticosteroids $(1,210$ vs 1,430$)$, whereas BMD values were similar. No differences were observed in osteocalcin and ALP between Early RA patients and healthy subjects at any time. Compared to healthy subjects, Early RA patients showed a significantly higher RANKL/OPG ratio and DKK1 serum levels, beginning from 6 month of observation, that correlated with disease activity (DAS28)
Conclusions: These preliminary data confirm that even in the early stages of disease, RA exert a negative effect on bone metabolism, whose pathogenesis is very complex and involves regulatory cytokines of bone homeostasis. This lead to a reduction of BMD and to changes of parameters of bone quality (TBS), that are more pronounced in patients treated with higher doses of corticosteroids compared to patients treated with lower corticosteroid doses

\section{REFERENCE:}

[1] Harvey NC, et al. Trabecular bone score (TBS) as a new complementary approach for osteoporosis evaluation in clinical practice. Bone 2015 Sep;78:216-24.

Disclosure of Interest: None declared

DOI: 10.1136/annrheumdis-2018-eular.2496

\section{THU0146 GLYCEMIC PROFILE AND INSULIN RESISTANCE IN PATIENTS WITH EARLY RHEUMATOID ARTHRITIS}

A.M. Brandy-García, A. Lorenzo Martín, S. Alonso Castro, M. Alperi López, F. J. Ballina García. Rheumatology, Hospital Universitario Central de Asturias, Oviedo, Spain

Background: In established rheumatoid arthritis (RA) there is a high incidence of patients with increased insulin resistance, which can favour the development of Diabetes Mellitus (DM) and the appearance of cardiovascular complications. These aspects, however, have not been studied in depth in patients with early rheumatoid arthritis

Objectives: To describe the glycemic profile and insulin resistance (IR) in patients with early diagnosis of RA who had not received any background treatment or steroids.

Methods: Observational study in which patients were included 18 years old, diagnosed with RA according to criteria ${ }^{A C R} 1987$ and/or , ${ }^{\text {ACR-EULAR } 2010}$ from the service of Arthritis of Recent Beginning of the Hospital Universitario Central de Asturias, between December 2016 and December 2017. In the basal visit, values of insulin, glucose fasting glycosylated haemoglobin ( $\mathrm{HbA} 1 \mathrm{c})$, body mass index (BMI) and abdominal perimeter were collected. In addition, $\mathrm{RI}$ and beta cell dysfunction were estimated with HOMA-IR and HOMA-B respectively.

Results: 66 patients were collected, of which 4 were excluded because they were known to be DM and 17 because they had not completed the analytical studies. Of the 45 that were finally studied, $80 \%$ (36 patients) are women, the mean age of $54.13 \pm 12.9$ years, the progression of the disease to diagnosis is $22.8 \pm 15.3$ weeks, $46.7 \%$ (21 patients) are FR and ACPA positive, and the mean disease activity measured by SDAl is $28.03 \pm 12.2$.

Eighteen patients $(45 \%)$ and $71.1 \%$ (31.5 patients) had HOMA-IR, with both 17 patients $(37.7 \%)$ showing a statistically significant association of $\mathrm{SDAl}>11$ $(p=0.001), B M l>24(p=0.03)$ and an increased abdominal perimeter $(p=0.013)$.

Based on the WHO's diagnostic criteria for DM, 2 patients (4.4\%) were diagnosed with DM (all based on a previously unknown $\mathrm{HbA} 1 \mathrm{c}>6.5 \%$ ) and $21(46.7 \%)$ as pre-diabetic (14 with glucose between 100-125,16 with $\mathrm{HbA} 1 \mathrm{c}>5.7$ and 9 patients with both alterations). In this subgroup the mean of HOMA-IR and HOMA-B was higher than the mean of the complete sample, 3.4 and 139 respectively. These patients compared with the rest of the sample had a statistically significant association with $\mathrm{BMI}>24(\mathrm{p}=0.07), \mathrm{SDAl}>11(\mathrm{p}=0.01)$.

No correlations were found between these metabolic alterations and the sex, age or positivity for $\mathrm{RH}$.

Conclusions: In patients with AR of less than one year of evolution and who have not received previous treatment with FAME or steroids, a high percentage of $\mathrm{RI}$, pancreatic B cell dysfunction and alterations of the glycemic profile are detected. These alterations are significantly correlated with the presence of overweight and obesity, as well as with the high degree of activity of the disease. Follow-up of these patients is necessary to determine the effect of therapy for rheumatoid arthritis on these metabolic alterations.

Disclosure of Interest: None declared

DOI: 10.1136/annrheumdis-2018-eular.5870

\section{THU0147 TREATMENT RESPONSE IN ANTIDEPRESSANTS- TREATED RA PATIENTS WITH DEPRESSIVE AND ANXIETY DISORDERS RECEIVING DMARDS AND BIOLOGICS ON A FIVE-YEAR FOLLOW-UP}

A. Abramkin ${ }^{1}$, T. Lisitsyna ${ }^{1}$, D. Veltishchev ${ }^{2}$, O. Seravina ${ }^{2}$, O. Kovalevskaya ${ }^{2}$, E. Nasonov $1 .{ }^{1}$ Nasonova Research Institute of Rheumatology; ${ }^{2}$ Moscow Research Institute of Psychiatry $\mathrm{MoH}$, Moscow, Russian Federation

Background: Anxiety and depressive disorders (ADD) significantly affect disease activity and prognosis, treatment compliance and response in rheumatoid 